Boise State University

ScholarWorks

9-8-2016

\title{
Boise State MILES Data Management Workflows
}

Jean Barney

Boise State University 


\section{Miles Data Publication Policy}

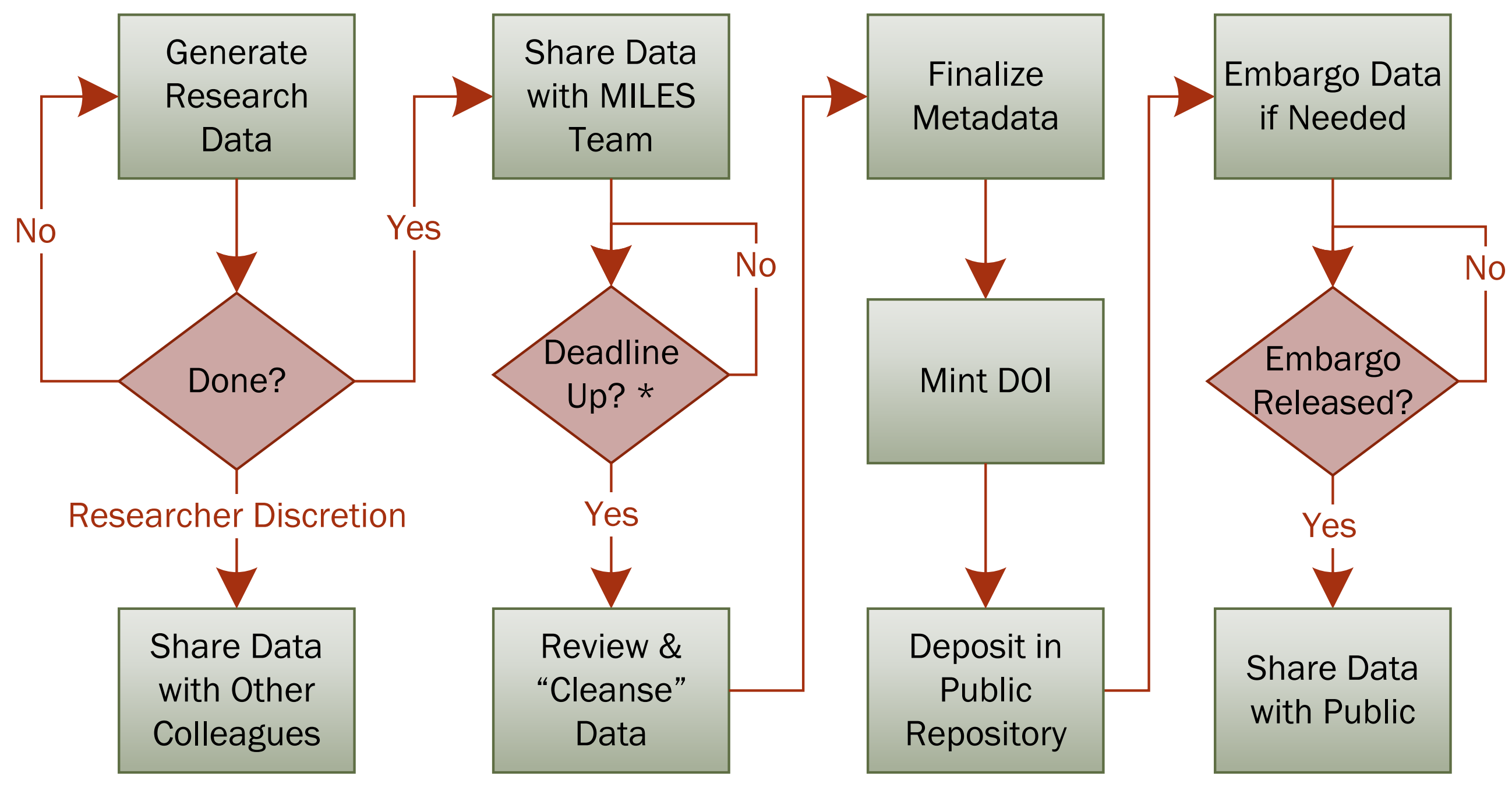

* Publication deadlines vary depending on type of data 


\section{Data Access Groups \& Their Roles}

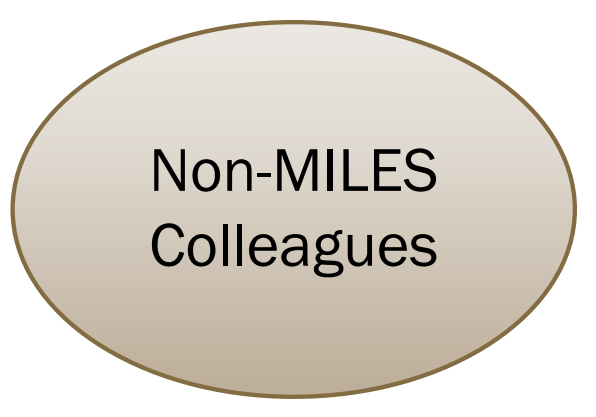

- Create \& Verify Data

- Draft Metadata

- Ingest Data

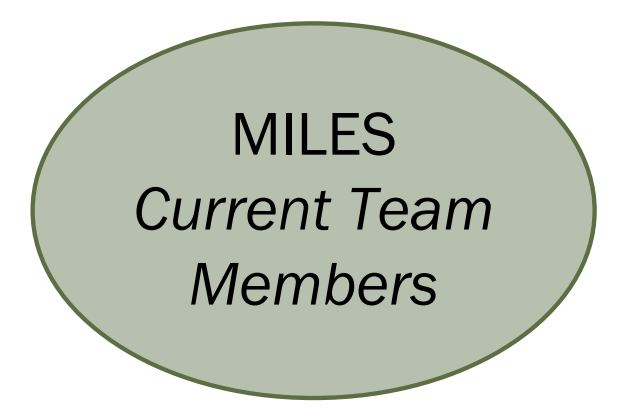

- Create \& Verify Data

- Draft Metadata

- Ingest Data

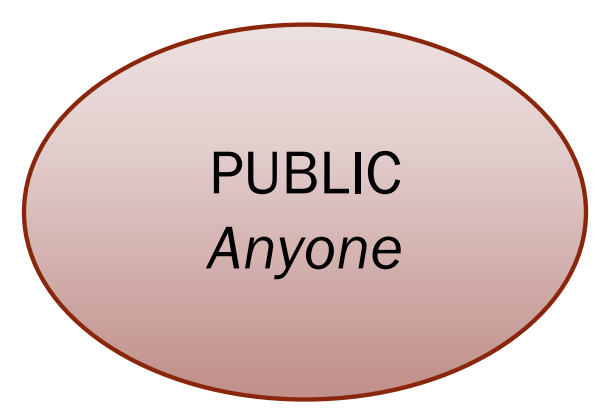

- Ingest Data

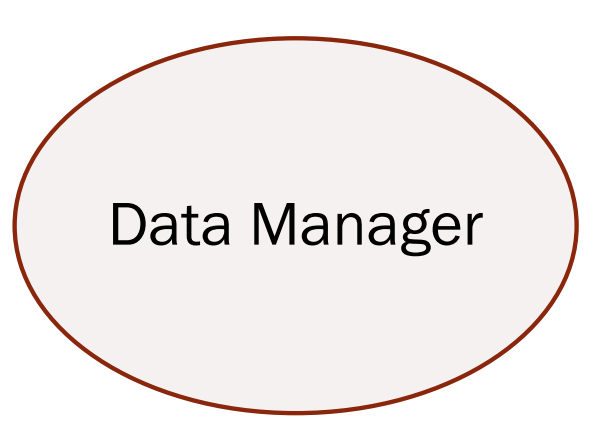

- Verify \& Catalog Metadata

- Publish Data per Policy

- Manage Data Submissions

- Manage Data Access

- Provide Training \& Support 


\section{Repository Design}
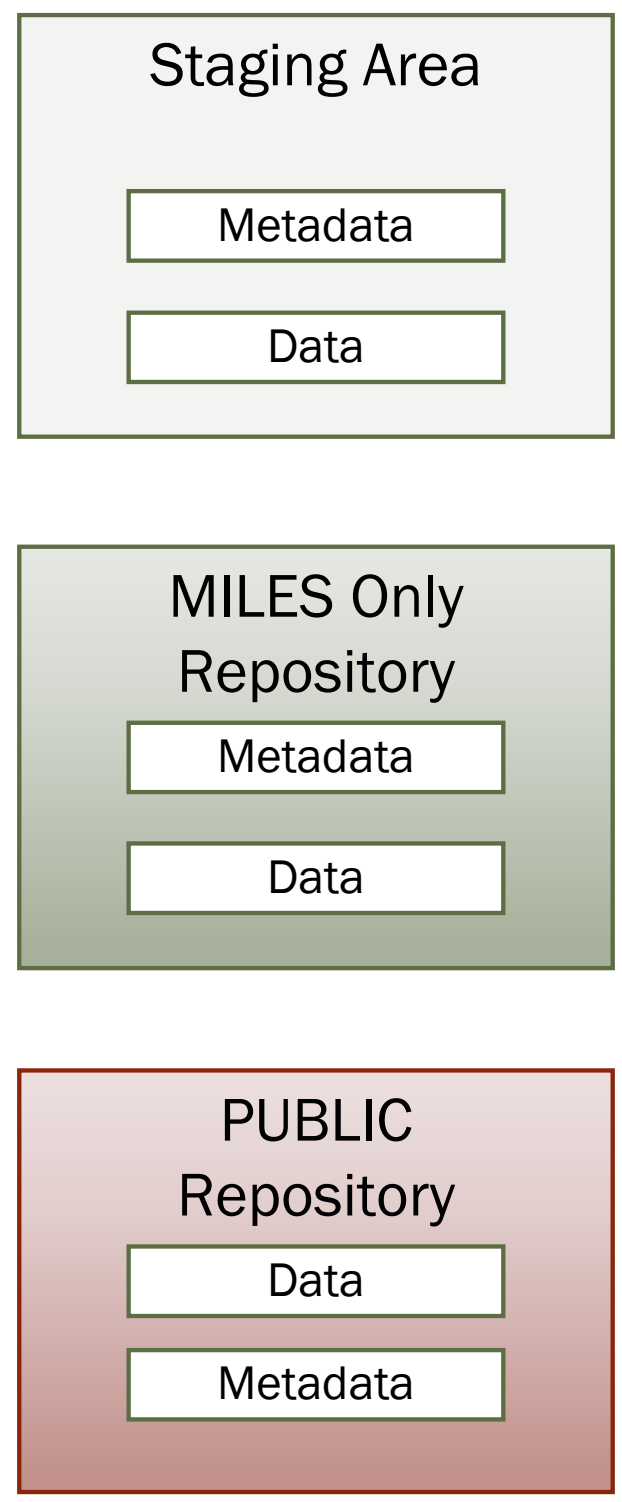


\title{
Repository Design Recommendation
}

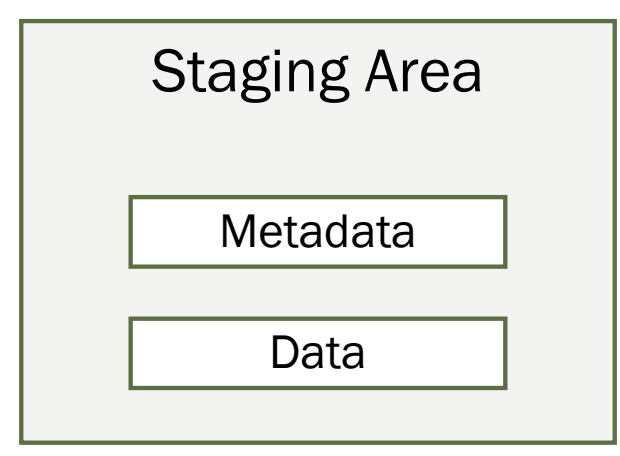

Secure Google

Drive

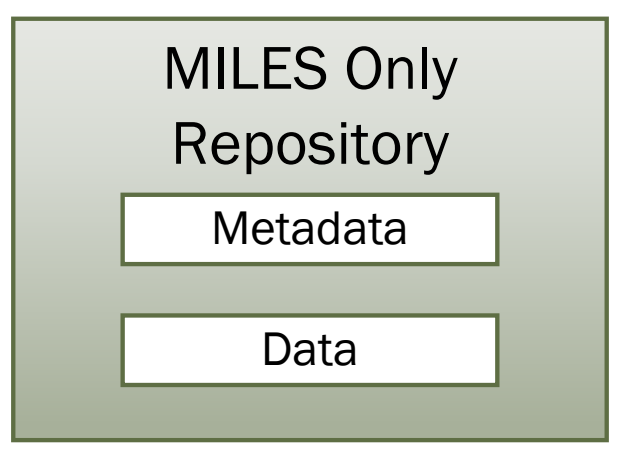

NKN OwnCloud

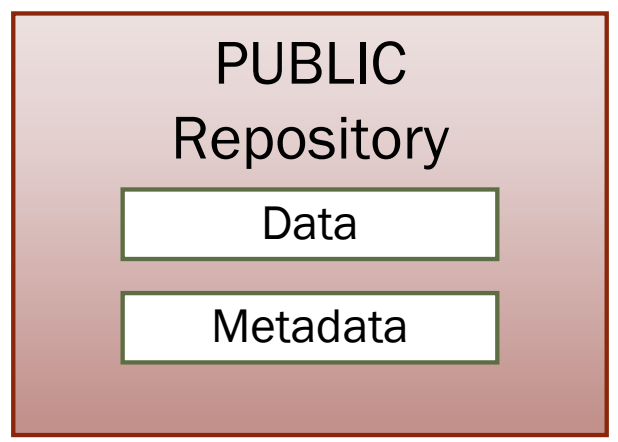

\author{
Boise State \\ ScholarWorks
}




\section{Publication Data Flow}

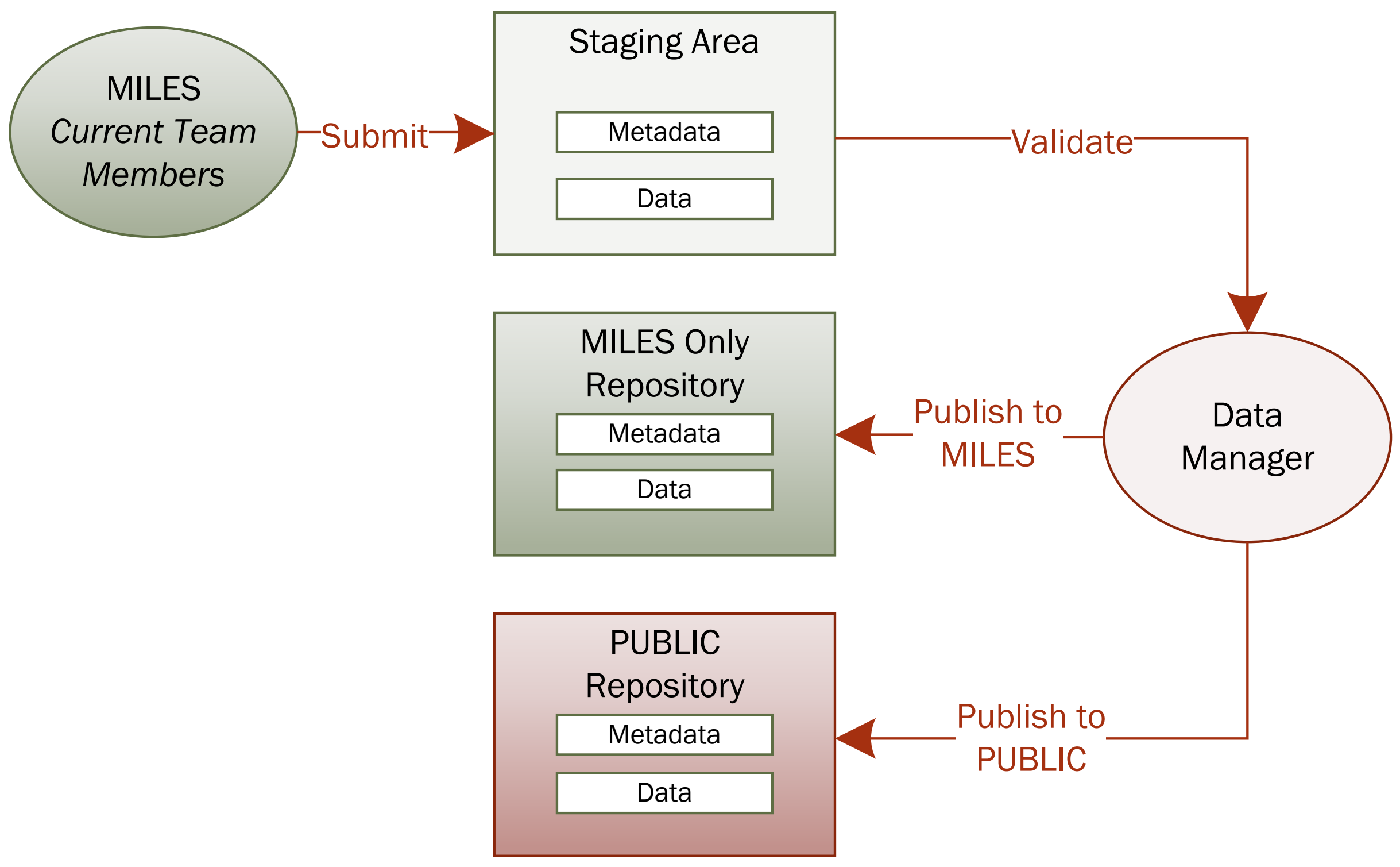




\section{Repository Access Rights}

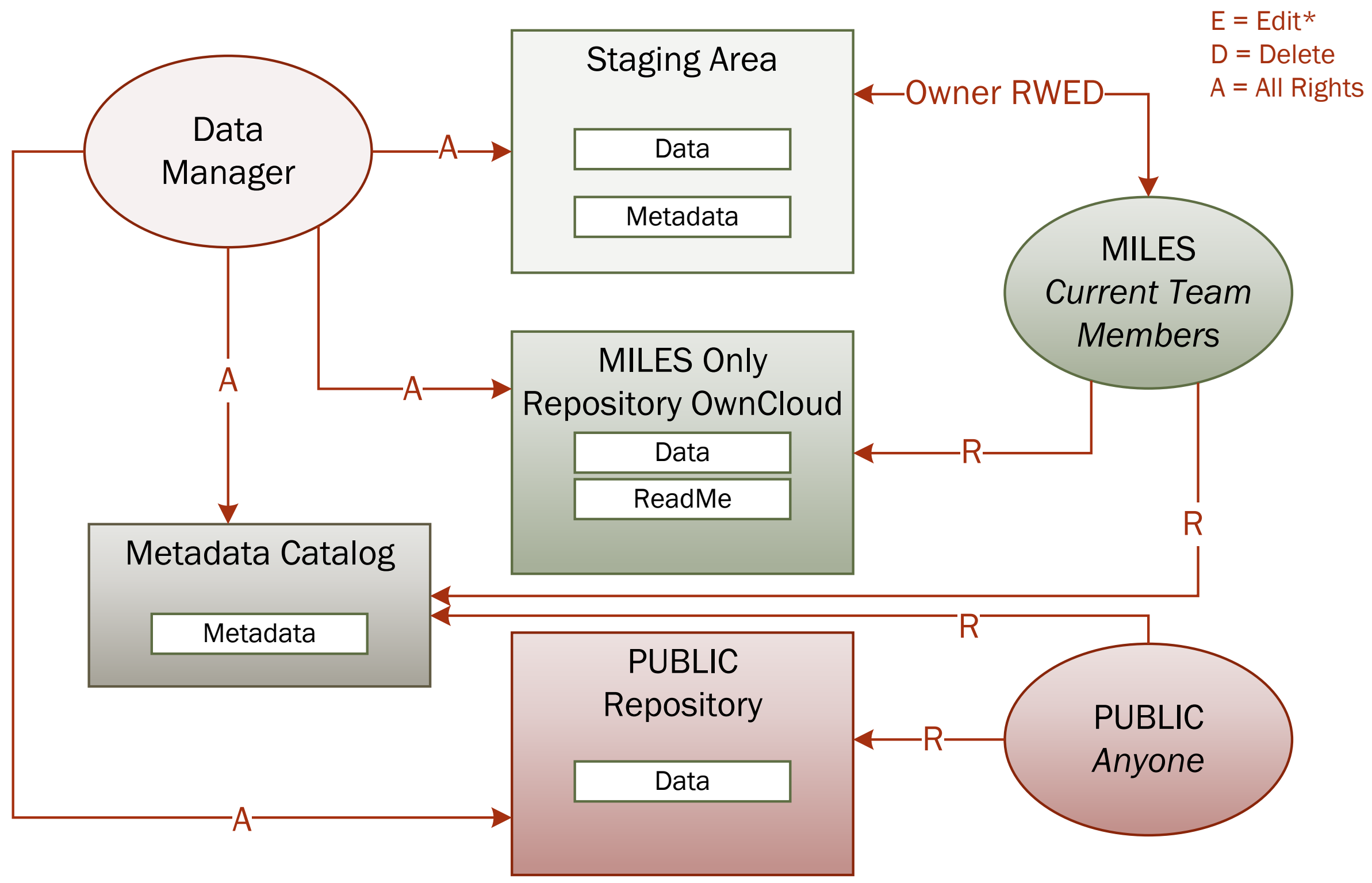

* $E=W$ on some operating systems 


\section{Public Repository - ScholarWorks}

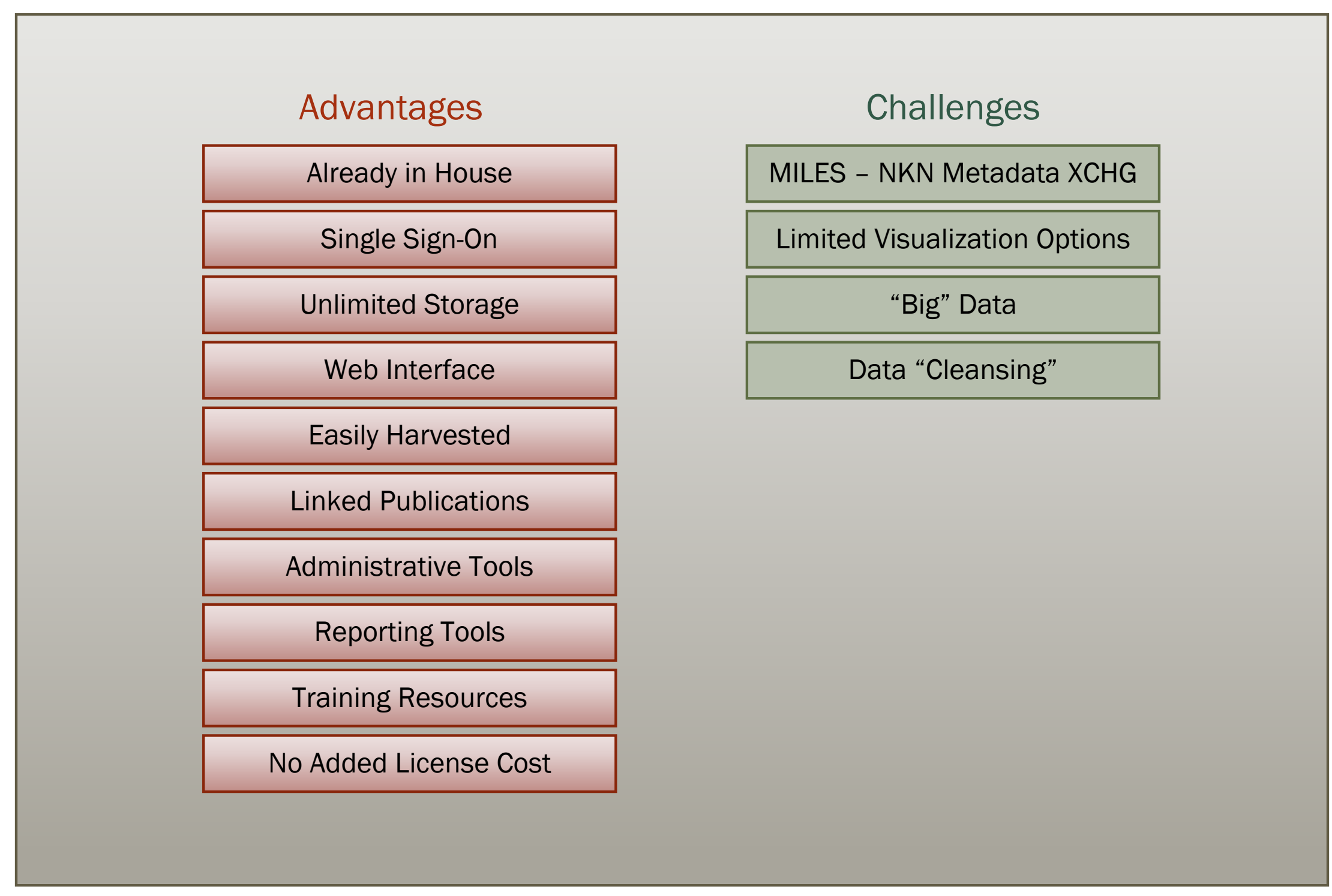

